\title{
The Effect of Isometric Hand Grip on Blood Pressure in Post Menopausal Hypertension
}

\author{
YASMEEN R. AHMED, M.Sc.*; HALA M. HANFY, Ph.D.*; WAFAA M. KAMAL, Ph.D.* and \\ MAHMOUD M. FOUAD, M.D.** \\ The Departments of Women Health, Faculty of Physical Therapy, Cairo University* and Obstetrics \& Gynecology, \\ Faculty of Medicine, Al-Azhar University**
}

\begin{abstract}
Background: The rate of hypertension increases after menopause. Whether estrogen and progesterone deficiency associated with menopause play a role in determining a worst blood pressure (BP). Hypertension (HTN) is the leading risk factor for mortality and morbidity. Isometric handgrip (IHG) training is a simple intervention endorsed by the American Heart Association as a potential adjuvant BP-lowering treatment.
\end{abstract}

Aim of Study: This current study was designed to investigate the effect of isometric hand grip exercise on blood pressure on postmenopausal hypertension.

Subjects and Methods: Forty post menopausal women participated in this study they complained from hypertension (diagnosed clinically byynecologist/physician), confirmed by sphygmomanometer instrument. They were selected randomly from outpatient clinic at Luxor general hospital, their age ranged from 50 to 65 years old, their body mass index were not exceed $35 \mathrm{~kg} / \mathrm{m}$. and their blood pressure ranged from $140 / 90$ to $180 / 110 \mathrm{~mm} / \mathrm{Hg}$. They were divided randomly into two groups equal in numbers, group A consisted of 20 post menopausal women who received antihypertensive drugs and isometric hand grip exercise (4 sessions/week for 6 weeks). While group B consisted of 20 postmenopausal women who received anti hypertensive drugs only. Blood pressure was assessed by stethoscope and mercury sphygmomanometer for all patients in both groups before and after treatment.

Results: The result of this study revealed that, there was a statistically highly significant decrease in the mean value of SBP in both group (A\&B) with percentage of improvement $12.0 \%$ and $8.4 \%$, respectively. There was significant decrease in the mean value of DBP in both group (A\&B) with percentage of improvement $16.27 \%$ and $9.47 \%$, respectively.

Conclusion: It could be concluded that the isometric hand grip exercise is a simple, cost free and non pharmacological method in reducing blood pressure in post menopausal women and can be used as adjunct method in treatment of hypertension in postmenopausal women.

Correspondence to: Dr. Yasmeen R. Ahmed,

The Department of Women Health, Faculty of Physical Therapy, Cairo University
Key Words: Isometric hand grip exercise - HypertensionPost menopause - Systolic blood pressure - Diastolic blood pressure.

\section{Introduction}

HYPERTENSION (HTN), defined as a systolic blood pressure (BP) $\geq 140 \mathrm{mmHg}$ and/or a diastolic $\mathrm{BP} \geq 90 \mathrm{mmHg}$, is a global epidemic. It is the leading cause of cardiovascular disease (CVD) and related mortalityworldwide, and is responsible for $\sim 10$ million deaths each year, making it a substantial contributor to global chronic disease burden. HTN is the most commonly diagnosed condition in primary care [1]

Uncontrolled HTN is associated with several sequelae that are damaging to the cardiovascular system. Long-term and potentially fatal blood pressure-related complications include coronary artery disease, heart failure, stroke, and renal failure, in addition to cognitive decline and overall poor quality of life [2,3].

Hypertension is one of the leading risk factors for cardiovascular disease. Aging in both men and women is characterized by increases in blood pressure (BP), but the age-related increases are more rapid in women than in men, and the prevalence of hypertension in post-menopausal women is higher than in men. In the world, in general, $25 \%$ of adult women are hypertensive [4]

Hypertensive postmenopausal women had more co morbid conditions than did non hypertensive women, control of hypertension has been shown to reduce the risk of stroke or death in those with stage I (or mild) hypertension [5]

Aerobic exercise training has consistently been shown to reduce BP and improve autonomic func- 
tion [6]. As detailed in recent meta-analyses (Owen, Wiles and Swaine, 2010) isometric handgrip (IHG) is intriguing exercise alternatives which require substantially less time ( $\sim 30-75$ total $\mathrm{min} /$ week) while documenting significant reductions in resting $\mathrm{BP}$ in normotensive and medicated hypertensive populations (similar to aerobic exercise training. isometric handgrip (IHG) training improved local, endothelium-dependent vasodilatation in medicated hypertensive patients [7]. The studies, suggested that an absence of female gonadal steroids may represent a major risk factor for postmenopausal hypertension. These findings indicate that female gonadal steroids are a protective factor against increases in blood pressure. Menopause-induced estrogen loss changes the characteristics of blood vessels and responses to vasoactive substances. Hence, estrogen clearly constitutes an important factor in controlling blood pressure, and appears to exert the opposite effects from testosterone for the control of blood pressure [8].

Furthermore, epidemiological data indicate that regular exposure to isometric activity at the workplace lowers the incidence of hypertension.

These findings suggest that isometric exercise training may become an important part of a non pharmacological intervention to prevent and combat hypertension) [9].

Isometric hand grip training may be especially beneficial for patients who:

a- Have difficulties continuing or increasing drugbased treatment care.

b- Are unable to attain BP control despite optimal treatment.

c- Have pre-HTN or low-risk stage I mild-HTN

d- Who wish to avoid medications or have less antihypertensive pill burden [10]

\section{Subject and Methods}

\section{Subjects:}

This study was carried out on a random sample of forty hypertensive post menopausal women and it was conducted for 6 weeks. The patients were chosen from Outpatient Department of Internal Medicine at Luxor general hospital in Luxor Governate (From August 2018 to January 2019). Their ages were ranged from (50-65) years old, their body mass index (BMI) didn't exceed 35 and their blood pressure from $140 / 90 \mathrm{mmHg}$ to $180 / 110 \mathrm{~mm}$ Hg. Duration of the study was 6 months.

All participants were given a full explanation of the treatment protocol and informed consent form had been signed by each women in both groups (A\& B) before participated in this study.

General characteristics of the women in both groups:

The mean values $( \pm$ SD) of age, weight, height and BMI in group $(\mathrm{A})$ were $54.75 \pm 3.02$ yrs., $80.35 \pm 6.43 \mathrm{~kg}, 1.62 \pm 0.04 \mathrm{~m}$ and $30.75 \pm 2.95 \mathrm{~kg} / \mathrm{m}^{2}$, respectively while in group B they were $55.75 \pm$ 3.64 yrs., $80.20 \pm 6.85 \mathrm{~kg}, 1.64 \pm 0.05 \mathrm{~m}$ and 29.85 $\pm 3.24 \mathrm{~kg} / \mathrm{m}^{2}$, respectively. Subjects with history of Hand burn, scar and contracture, with tendon cut in hand, subjects with cardiac disease and Right hemiplegic patient (left stroke) were excluded from the study.

\section{Instrumentation:}

\section{Stethoscope:}

Mercury column sphygmomanometer: To measure blood pressure in both groups (A\&B) pre \& post treatment.

Hand grip dynamometer to determine maximum voluntary contraction (MCV).

Spring loaded hand grip device:

Easily adjust resistance level from (10 to $40 \mathrm{~kg}$ ):

- Comfortable anti slip handles fit any hand size.

- High quality stainless steel tension springs provide long lasting [11]

\section{Measurements:}

\section{1-Measurement of arterial blood pressure:}

The procedure was carefully and clearly explained to each womenin both groups $(A) \&(B)$, arterial blood pressure was measured from right arm while the participant was in sitting position. Three trials for measurement of blood pressure was taken then the mean was calculated before and after the end treatment ( 6 weeks). Participants were required to abstain from exercise 24 hours before all measurements were taken by the same investigator.

\section{2- Measurement of subject maximum voluntary contraction (MVC):}

By using hand grip dynamometer, value was be determined as highest value obtain in three attempts. The purpose of using a hand dynamometer is to measure the maximum isometric strength of the hand and forearm muscles. The hand dynamometer could be adjusted for hand size and must be calibrated regularly for consistent results. The patients held the dynamometer in the right hand being tested, with the arm at right angles with the 
elbow by the side of the body. Adjust the handle of the dynamometer as necessary, making sure that the base rests on the first metacarpal (heel of the palm), while the handle rests on the middle of the four fingers. The patients then squeeze the hand dynamometer with maximum isometric effort for at least 5 seconds. The patient was required to not move any other part of the body and was encouraged to use maximum effort.

\section{c- Treatment procedures:}

All women had full illustration as well as, explanation about the protocol of the study and sign a written approved consent form before the study.

Duration of the study: $15 \mathrm{~min}$. Frequency: 4 times per week, for 6 weeks. position of woman: Sitting position with back supported, and the working arm extended forward.

1- The anti hypertensive drug with the same dose for all patients was given for both groups (A) $\&$ (B) all through the study period (6 weeks).

2- Isometric hand grip exercise was performed by 20 patients (group A) by using spring loaded hand grip with a resistance level that approximated $30 \%$ to $40 \%$ of their MVCs for 4 sessions/ week for 6 weeks and home training exercise was explained to the patients.

3- Before starting first treatment session, each patient was instructed briefly about the treatment procedure, which was explained carefully to her to gain confidence and cooperation.

4- Women were in sitting position during training with the working arm extended toward front.

5- Before each training session each subject's maximum voluntary contraction (MVC) value was determined by hand grip dynamometer as the highest value obtained on three attempts.

6- Patients performed four bouts ( $3 \mathrm{~min}$ ) of isometric hand grip exercise with the dominant hand by using spring isometric hand grip device at $30 \%$ of maximum voluntary contraction (MVC).

7- Each bout was separated by $5 \mathrm{~min}$ rest period.

8- 20 subjects (Group B) didn't train and served as control group.

\section{Dataanalysis:}

Measured data were analyzed and their mean values and standard deviation were calculated. Test of normality, Kolmogorov-Smirnov test, was used to measure the distribution of data measured premeasure the distribution of data measured pretreatment:
- Accordingly, comparison between normally distributed variables in the two groups was performed using unpaired $t$-test. Analysis of covariance (ANCOVA) test was used to compare the post-treatment values of the two groups on controlling the effect of pre-treatment value. Bonferroni correction test was used to compare within group (pre-vs post-treatment) differences.

- Statistical Package for Social Sciences (SPSS) computer program (version 19 windows) was used for data analysis. $p$-value $\leq 0.05$ was considered significant.

\section{Results}

\section{1- Demographic data:}

I- General characteristics of the women in both groups:

The mean values ( $\pm \mathrm{SD}$ ) of age, weight, height and BMI in group (A) study group were $54.75 \pm 3.02$ yrs., $80.35 \pm 6.43 \mathrm{~kg}, 1.62 \pm 0.04 \mathrm{~m}$ and $30.75 \pm 2.95$ $\mathrm{kg} / \mathrm{m}^{2}$, respectively while in group (B) control group they were $55.75 \pm 3.64 \mathrm{yrs} ., 80.20 \pm 6.85 \mathrm{~kg}$, $1.64 \pm 0.05 \mathrm{~m}$ and $29.85 \pm 3.24 \mathrm{~kg} / \mathrm{m}^{2}$, respectively.

There was no statistical significant difference between the two groups as regards age ( $t=-0.945$, $p=0.351)$, weight $(t=0.071 ; p=0.943)$, height $(t=1.624 ; p=0.113)$ and BMI $(t=0.927 ; p=0.360)$ (Table 1, Figs. 1-4).

Table (1): Physical characteristics in the two studied groups.

\begin{tabular}{lcccc}
\hline & $\begin{array}{c}\text { Group A } \\
(\mathrm{n}=20)\end{array}$ & $\begin{array}{c}\text { Group B } \\
(\mathrm{n}=20)\end{array}$ & $\begin{array}{c}t \text { - } \\
\text { value }\end{array}$ & $\begin{array}{c}p \text { - } \\
\text { value }\end{array}$ \\
\hline Age (yrs.) & $54.75 \pm 3.02$ & $55.75 \pm 3.64$ & -0.945 & $0.351(\mathrm{NS})$ \\
Weight (kg.) & $80.35 \pm 6.43$ & $80.20 \pm 6.85$ & 0.071 & $0.943(\mathrm{NS})$ \\
Height (m) & $1.62 \pm 0.04$ & $1.64 \pm 0.05$ & -1.624 & $0.113(\mathrm{NS})$ \\
BMI $\left(\mathrm{kg} / \mathrm{m}^{2}\right)$ & $30.75 \pm 2.95$ & $29.85 \pm 3.24$ & 0.927 & $0.360(\mathrm{NS})$ \\
\hline
\end{tabular}

Data are expressed as mean \pm SD.

$\mathrm{NS}=p>0.05=$ Not significant.

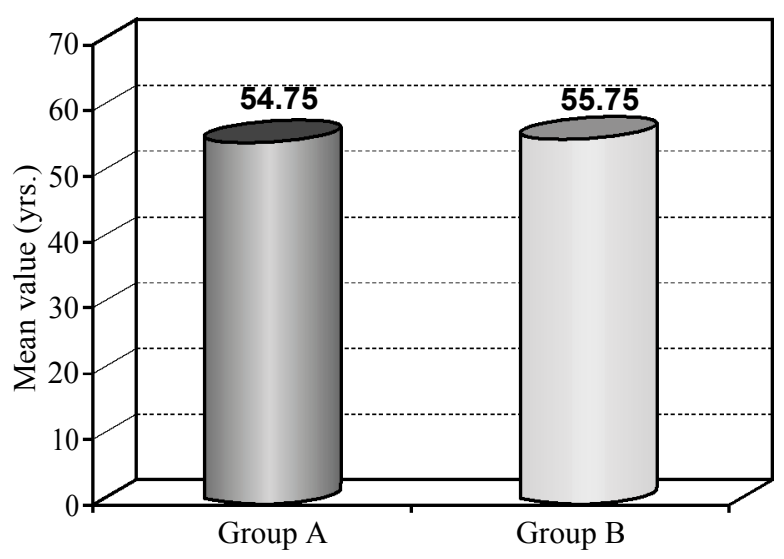

Fig. (1): Mean values of age in both groups. 


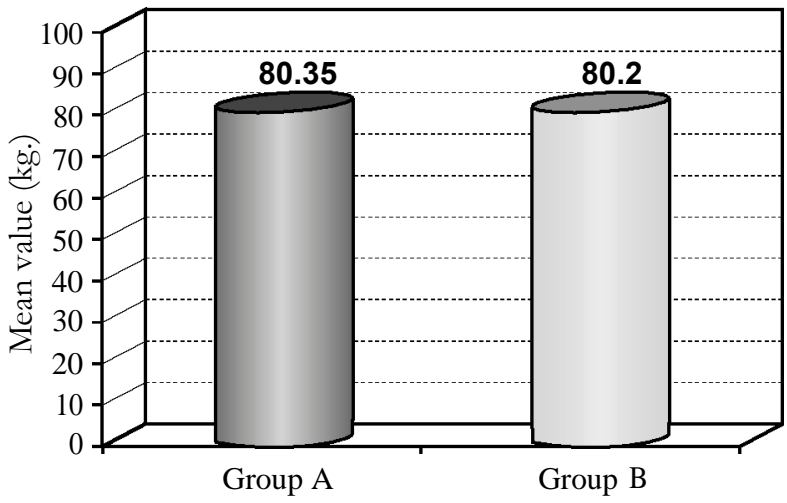

Fig. (2): Mean values of weight in both groups.

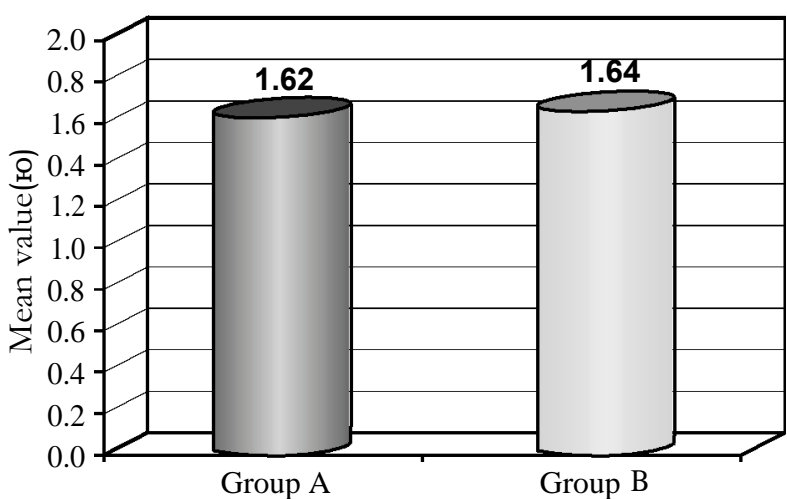

Fig. (3): Mean values of height in both groups.

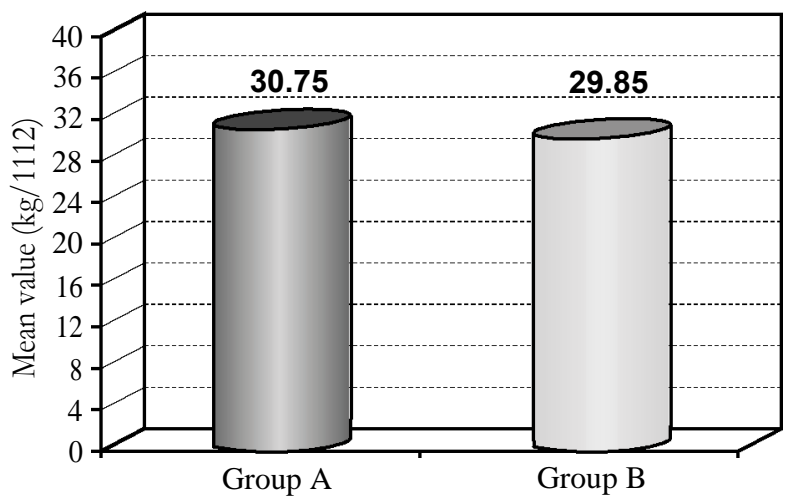

Fig. (4): Mean values of BMI in both groups.

\section{Diastolic blood pressure (DBP):}

Within group comparison (intra group comparison):

In group A, there was a statistical significant decrease in the mean value of DBP measured at post-treatment $(79.75 \pm 6.38)$ when compared with its corresponding value measured at pre-treatment (95.25 \pm 5.25$)$ with $p$-value $=0.001$ (Table 2, Fig. 5).

Also in group B, there was a statistical significant decrease in the mean value of DBP measured at post-treatment $(86.00 \pm 6.20)$ when compared with its corresponding value measured at pretreatment $(95.00 \pm 5.13)$ with $p$-value $=0.001$ (Table 2, Fig. 5).
The percent decrease in DBP level in both groups A and B were $16.27 \%$ and $9.47 \%$, respectively (Table 2).

\section{Between groups comparison:}

At pre-treatment, in groups $\mathrm{A}$ and $\mathrm{B}$, the mean values $( \pm$ SD) of DBP were $95.25 \pm 5.25$ and 95.00 \pm 5.13 , respectively. There was no statistical significant difference between the two groups $(\mathrm{F}=0.023$ $\& p=0.880)$ (Table 2$)$.

ANCOVA test was used to compare the posttreatment values of the two groups on controlling the effect of pre-treatment value. The results of $\mathrm{DBP}$ revealed that there was a statistical significant decrease in its level in group A $(79.75 \pm 6.38)$ when compared with its corresponding level in group B (86.00 \pm 6.20$)(\mathrm{F}=16.755 \& p=0.001)$ (Table 2, Fig. 5).

Table (2): Comparison between mean values of DBP in the two studied groups measured at pre- and posttreatment.

\begin{tabular}{lllll}
\hline & $\begin{array}{c}\text { Group A } \\
(\mathrm{n}=20)\end{array}$ & $\begin{array}{c}\text { Group B } \\
(\mathrm{n}=20)\end{array}$ & $\begin{array}{c}\mathrm{F}- \\
\text { value }\end{array}$ & $\begin{array}{c}p- \\
\text { value }\end{array}$ \\
\hline Pre-treatment & $95.25 \pm 5.25$ & $95.00 \pm 5.13$ & 0.023 & $0.880(\mathrm{NS})$ \\
Post-treatment & $79.75 \pm 6.38$ & $86.00 \pm 6.20$ & 16.755 & $0.001(\mathrm{~S})$ \\
Mean difference & 15.5 & 9.0 & & \\
$\%$ change & $16.27 \downarrow \downarrow$ & $9.47 \downarrow \downarrow$ & & \\
$p$-value & $0.001(\mathrm{~S})$ & $0.001(\mathrm{~S})$ & & \\
\hline
\end{tabular}

Data are expressed as mean \pm SD. $\quad$ F-value $=$ ANCOVA test NS $=p>0.05=$ Not significant .

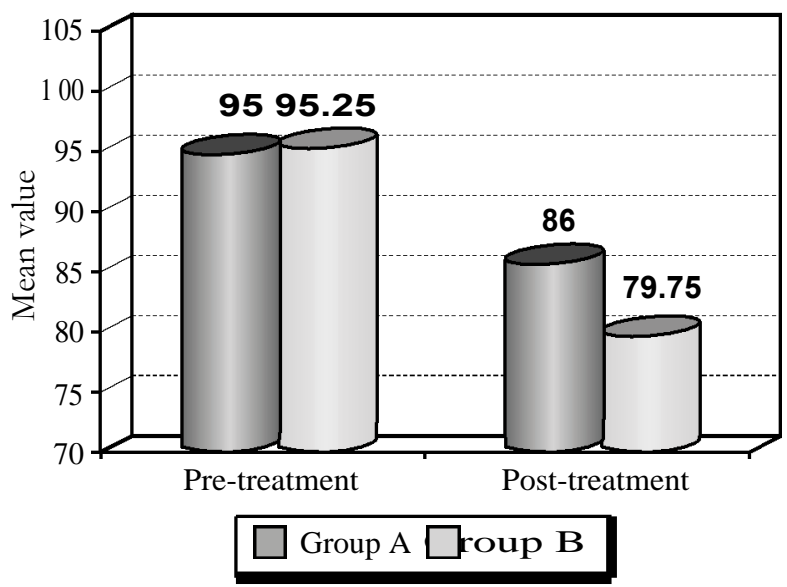

Fig. (5): Mean values of DBP in the two studied groups measured pre- and post-treatment.

Systolic blood pressure (SBP):

Within group comparison (intra group comparison):

In group A, there was a statistical significant decrease in the mean value of SBP measured at post-treatment (137.50 111.06$)$ when compared with its corresponding value measured at pretreatment $(156.25 \pm 10.75)$ with $p$-value $=0.001(\mathrm{Ta}$ ble, Fig.). 
Also in group B, there was a statistical significant decrease in the mean value of SBP measured at post-treatment $(141.75 \pm 13.01)$ when compared with its corresponding value measured at pretreatment $(154.75 \pm 11.29)$ with $p$-value $=0.001$ (Table 3, Fig. 6).

The percent decrease in SBP level in both groups A and B were $12.0 \%$ and $8.4 \%$, respectively (Table 3).

\section{Between groups comparison:}

At pre-treatment, in groups $\mathrm{A}$ and $\mathrm{B}$, the mean values $( \pm$ SD) of SBP were $156.25 \pm 10.75$ and $154.75 \pm 11.29$, respectively. There was no statistical significant difference between the two groups $(\mathrm{F}=0.185 \& p=0.669)$ (Table 3).

ANCOVA test revealed that there was a statistical significant decrease in the mean value of SBP in group A (137.50 \pm 11.06$)$ when compared with its corresponding level in group B (141.75 \pm 13.01$)$ $(\mathrm{F}=11.364 \& p=0.002)$ (Table 3, Fig. 6).

Table (3): Comparison between mean values of SBP in the two studied groups measured at pre- and posttreatment.

\begin{tabular}{lllll}
\hline & \multicolumn{1}{c}{$\begin{array}{c}\text { Group A } \\
(\mathrm{n}=20)\end{array}$} & $\begin{array}{c}\text { Group B } \\
(\mathrm{n}=20)\end{array}$ & $\begin{array}{c}\text { F- } \\
\text { value }\end{array}$ & $\begin{array}{c}p \text { - } \\
\text { value }\end{array}$ \\
\hline Pre-treatment & $156.25 \pm 10.75$ & $154.75 \pm 11.29$ & 0.185 & $0.669(\mathrm{NS})$ \\
Post-treatment & $137.50 \pm 11.06$ & $141.75 \pm 13.01$ & 11.364 & $0.002(\mathrm{~S})$ \\
Mean difference & 18.75 & 13.00 & & \\
$\%$ change & $12.00 \downarrow \downarrow$ & $8.40 \downarrow \downarrow$ & & \\
$p$-value & $0.001(\mathrm{~S})$ & $0.001(\mathrm{~S})$ & & \\
\hline
\end{tabular}

Data are expressed as mean $\pm \mathrm{SD}$.

$\mathrm{F}$-value $=$ ANCOVA test

NS $=p>0.05=$ Not significant

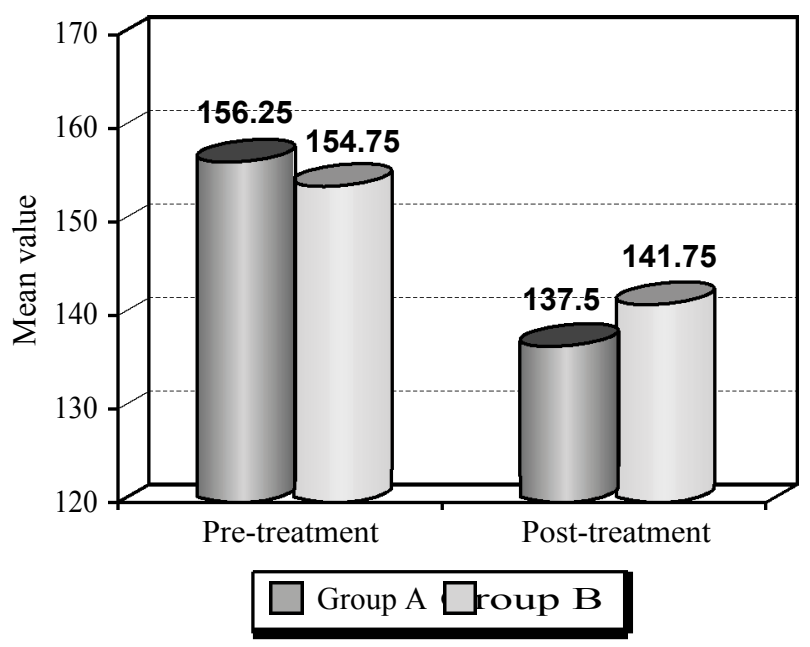

Fig. (6): Mean values of SBP in the two studied groups measured pre- and post-treatment.

\section{Discussion}

In our study, there was there was a statistically highly significant decrease in the mean value of SBP in both group (A\&B) with percentage of improvement $12.0 \%$ and $8.4 \%$, respectively. There was significant decrease in the mean value of DBP in both group (A\&B) with percentage of improvement $16.27 \%$ and $9.47 \%$, respectively.

The result of the study agreed with those of Owen et al., (2010) who found that a simple programme of isometric exercise, in bouts of $20 \mathrm{~min}$ undertaken three times a week, with a weekly exercise time of $1 \mathrm{~h}$, can reduce systolic blood pressure by about $10 \mathrm{mmHg}$ and diastolic blood pressure by about $7 \mathrm{mmHg}$, in $<10$ weeks. These are very substantial reductions, comparable with those achieved with a single pharmacological agent and substantially more than the $3 \mathrm{mmHg}$ or so reduction resulting from regular dynamic exercise 3 or from resistance exercise. The greater reductions in resting blood pressure for isometric exercise compared with other modes of exercise suggest that there might be a more powerful effect on resting blood pressure from isometric exercise [13]

The result of the study agreed with those of Garg, Rinku et al., (2014) who found that after 10 weeks of IHG training performing $3 \mathrm{~min}$ bouts of IHG exercise separated by 5 minute rest period for 3 times weekly for 10 weeks, there was a significant reduction in resting systolic and diastolic blood pressure. IHG might be simple, cost effective and non-pharmacological method in decreasing blood pressure [14].

The result of this study agreed with those of Devereux et al., (2015) who found that 4 weeks of Isometric Exercise Training induced changes in immediate post-exercise blood pressure and index of baroreflex sensitivity responses. Furthermore, these altered immediate responses were associated with training-induced reductions in resting blood pressure. This is the first suggestion that very shortterm (immediate) cardiovascular responses following isometric exercise may be important in defining chronic reductions in resting SBP following a period of IET. The significant difference in immediate post-exercise SBP slope intercept suggests that chronic exposure to an isometric exercise stimulus may alter post-exercise SBP control. Adaptations in immediate post-exercise responses may be important in defining resting SBP adaptations to isometric exercise training, as evidenced by the correlation between individual adaptations 
in immediate post-exercise responses and traininginduced reductions in resting SBP [15].

The result of these study agreed with those Farah et al., (2017) who found that isometric handgrip training has been considered a promising intervention to reduce cardiovascular risk in adults, given the positive effects on cardiovascular variables. meta-analytical study showed a reduction in systolic blood pressure of $5 \mathrm{mmHg}$ in hypertensive. Another advantage of the handgrip exercise is its easy implementation that allows it to be carried anywhere, including at home [16]

\section{Conclusion:}

It could be concluded that the isometric hand grip exercise is a simple, cost free and non pharmacological method in reducing blood pressure in post menopausal women and can be used as adjunct method in treatment of hypertension in postmenopausal women.

\section{References}

1- CHOBANIAN A.V., BAKRIS G.L., BLACK H.R., CUSHMAN W.C., GREEN L.A., IZZO Jr. J.L. and ROCCELLA E.J.: The seventh report of the joint national committee on prevention, detection, evaluation, and treatment of high blood pressure: The JNC 7 report. Jama, 289 (19): 2560-2571, 2003.

2- HALL J.E., GRANGER J.P., RECKELHOFF J.F. and SANDBERG K.: Hypertension and cardiovascular disease in women. Hypertension, 51(4): 951-951, 2008.

3- LIMA R., WOFFORD M. and RECKELHOFF J.F.: 'NIH Public Access', 14 (3): pp. 254-260. doi: 10.1007/s11906012-0260-0.Hypertension, 2013.

4- YANES L.L. and RECKELHOFF J.F.: 'Postmenopausalhypert-ension',American Journal of Hypertension. Nature Publishing Group, 24 (7): pp. 740-749, 2011.

5- WASSERTHEIL-SMOLLER S., ANDERSON G., PSATY B.M., BLACK H.R., MANSON J., WONG N. and LASSER N.: Hypertension and its treatment in postmenopausal women: Baseline data from the Women's Health Initiative. Hypertension, 36 (5): 780-789, 2000.

6- FREEMAN A.J., VINH A. and WIDDOP R.E.: 'Novel approaches for treating hypertension', F1000Research, 6 (0): p. 80, 2017.
7- ZOKVIC M.A.: Isometric handgrip training-induced reductions in blood pressure: The influence of age and cardiovascular reactivity as an outcome predictor in normotensive women, 2017.

8- IZUMI Y., MATSUMOTO K., OZAWA Y., KASAMAKI Y., SHINNDO A., OHTA M. and KAWAMURA H.: Effect of age at menopause on blood pressure in postmenopausal women. American Journal of Hypertension, 20 (10): 1045-1050, 2007.

9- RAY C.A. and CARRASCO D.I.: 'Isometric handgrip training reduces arterial pressure at rest without changes in sympathetic nerve activity.', American Journal of Physiology. Heart and cIrculatory Physiology, 279 (1): pp. H245-H249, 2000.

10-McGOWAN C.L., PROCTOR D.N., SWAINE I., BROOK R.D., JACKSON E.A. and LEVY P.D.: Isometric handgrip as an adjunct for blood pressure control: A primer for clinicians. Current Hypertension Reports, 19 (6): 51, 2017.

11- MILLAR P.J., BRAY S.R., MacDONALD M.J. and McCaRTNEY N.: The hypotensive effects of isometric handgrip training using an inexpensive spring handgrip training device. Journal of Cardiopulmonary Rehabilitation and Prevention, 28 (3): 203-207, 2008.

12- MILLAR P.J., MACDONALD M.J., BRAY S.R. and McCARTNEY N.: Isometric handgrip exercise improves acute neurocardiac regulation. European Journal of Applied Physiology, 107 (5): 509, 2009.

13- OWEN A., WILES J. and SWAINE I.: 'Effect of isometric exercise on resting blood pressure: A meta analysis', Journal of Human Hypertension. Nature Publishing Group, 24 (12): pp. 796-800, 2010.

14- GARG R., MALHOTRA V., KUMAR A., DHAR U. and TRIPATHI Y.: Effect of isometric handgrip exercise training on resting blood pressure in normal healthy adults. Journal of clinical and diagnostic research: JCDR, 8 (9): BC08.

15- DEVEREUX G.R., WILES J.D. and HOWDEN R.: Immediate post-isometric exercise cardiovascular responses are associated with training-induced resting systolic blood pressure reductions. European Journal of Applied Physiology, 115 (2): 327-333, 2015.

16- FARAH B.Q., VIANNA L.C., RODRIGUES S.L.C., CORREIA M.A., TEIXEIRA A.L., ANDRADE F. and CUCATO G.G.: Effects of isometric handgrip training in patients with cardiovascular disease: rationale and design of the ISOPRESS network. Motriz: Revista de Educação Física, 23 (4), 2017. 


\section{تأثير تمرين مقاومة اليد على ضغط الدم بعد أنقطاع الطمث معالئ}

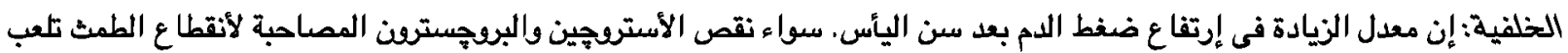

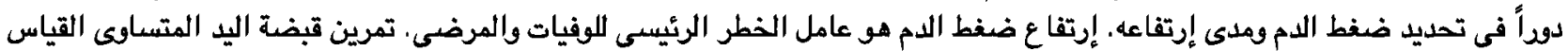

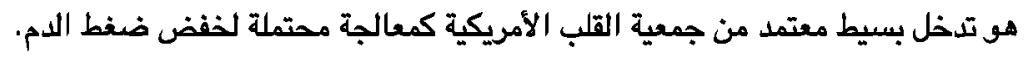

الفرض: تم تصميم هذه الدراسة الحالية للتحقق من تأثير ممارسة اليد متساوى القياس على ضغط الدم بعد أنقطاع الطمث.

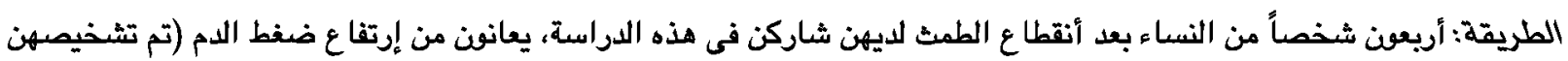

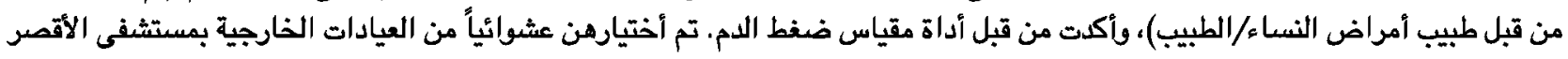

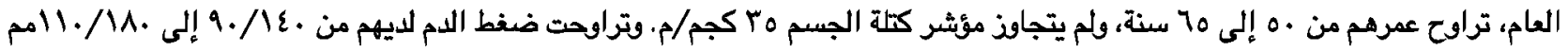

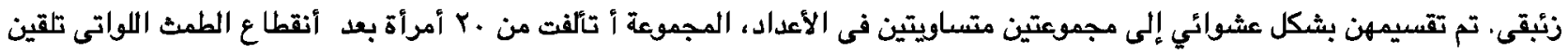

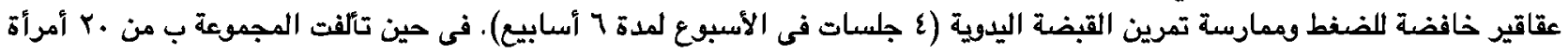
بعد سمن اليأس تلقين أدوية إرتفاع ضغط الدم فقط. تم تقييم ضغط الدم بواسطة السماعة الطبية والزئيق لجميع المرضى فئى في كلا المجموعتين قبل وبعد العلاج.

النتائج: أظهرت نتائج هذه الدراسة أنه كان هناك إنخفاض ذو دلالة إحصائية كبيرة فى متوسط قيمة الضغط الأنبساطى فى المجموعتين

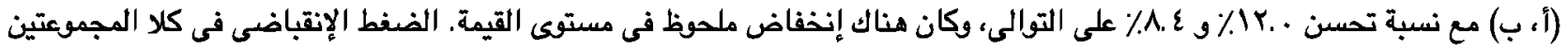

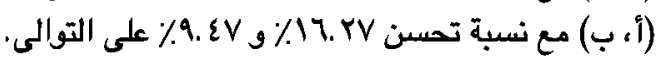

الخلاصهة: يمكن الأستنتاج أن التمرين اليوى المتساوى هو طريقة بسيطة وخالية من التكلفة وغير دوائية فى خفض ضغط الدم عند النساء

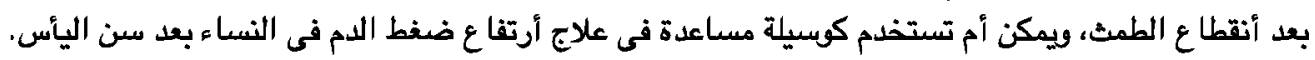

